\title{
ICCNS-sponsored meetings
}

\section{Bernard Perbal}

Published online: 30 November 2011

(C) The International CCN Society 2011

Dear Members of the ICCNS,

Dear Colleague,

At the dawn of the 12th birthday of the ICCNS, it is a great pleasure to write this end-of -the-year Editorial and share with you an overview of our progress.

This year has been the time for great changes and improvements.

Among these and for the first time since it was created, the ICCNS has officially sponsored a scientific meeting (http:// www.ccnsociety.com/targets_2011/index.html) which was outside of the regular biannual International workshops on the CCN family of genes.

Thanks to Andrew Leask and other co-organizers who helped him, the Vancouver meeting was a success and opened the road for new ones.

As I had previously suggested at the 6th CCN workshop in Ireland the idea is to broaden the activity of our society and make our family of proteins known by scientists working in fields that overlap ours.

Actually, this was and remains one of the very original objectives of the ICCNS.

The ICCNS is ready to sponsor and provide help for organizing meetings dealing with all aspects related to signaling and cellular communication in normal and pathological conditions.

Those who wish to organize such ICCNS-sponsored meetings should proceed as follows:

1) submit a short written proposal and send it directly to the ICCNS bureau (ccnsociety@yahoo.com)who will centralize, file and forward the various applications to

\footnotetext{
B. Perbal $(\bowtie)$

President of the ICCNS,

Paris, France

e-mail: bperbal@gmail.com
}

the President elect (presently Professor Masaharu Takigawa).

2) provide in the application a rough estimate of the meeting cost and a rough number of expected attendees.

3) the application should also provide details as to the type and amount of local or external funding that is expected.

The President Elect will consult members of the Scientific Board and scientists outside of the CCN Society, in order to evaluate the feasibility and potential interest of the proposed meeting.

Once the President elect has selected the meeting proposals, a decision will be made with the Executive Board of the ICCNS.

Please do not hesitate to send us your suggestions

In any case, these interim meetings are not meant to replace or substitute the regular biannual Workshops on the family of $\mathrm{CCN}$ Genes, that remain the major activity sponsored by ICCNS and organized by ICCNS members.

The next workshop will be held October 21-24th 2012 in Sydney and might possibly be followed by a come back to Saint-Malo in 2014!

Discussions regarding these events have already been initiated and should be confirmed shortly.

Another major achievement was reached with our society journal JCCS.

Thanks to Andrew Leask and all the authors who have shown strong support to the journal, citations of JCCS manuscripts increase at a fast pace and we should be soon in a position to apply for an Impact factor at ISI.

Right now, our unofficial IF is between 2 and 3.

A series of special issues featuring topics of interest should help us in reinforcing our position in the competitive field of publication. 
As previously stated on several occasions, active ICCNS membership is important and we need you to help us in maintaining the high quality of science that we sponsor and publish.

Attracting more members and consolidating our strength will depend upon your help.
The ICCNS is yours and we count on you.

Let me take this occasion to wish you all the best for the end of 2011 and hope that we can all meet in Sydney next year.

Professor Bernard PERBAL

Executive President of the ICCNS 